Article

\title{
Technical Route to Achieve Ultra-Low Emission of Nitrogen Oxides with Predictive Model of Nitrogen Oxide Background Concentration
}

\author{
Yanfei Yao and Yanxin Chen * \\ College of Materials Science and Engineering, Xi'an University of Architecture and Technology, \\ Xi'an 710055, China; yaoyanfei@xauat.edu.cn \\ * Correspondence: chenyanxin@xauat.edu.cn; Tel.: +86-1309-697-3109
}

Received: 30 June 2020; Accepted: 3 September 2020; Published: 4 September 2020

check for updates

\begin{abstract}
As the most mature denitration technology in the cement clinker burning process, selective non-catalytic reduction (SNCR) has been unable to meet the requirements of ultra-low nitrogen oxide $\left(\mathrm{NO}_{\mathrm{X}}\right.$ ) emissions under low ammonia escape, thus a hybrid denitration process based on SNCR was established. The process had three steps: reducing the $\mathrm{NO}_{X}$ background concentration (NBC), implementing staged combustion, and optimizing the effect of the SNCR. One of the keys to this process was the real-time acquisition of the NBC. In this paper, a multivariate linear regression model for the prediction of NBC was constructed and applied to one $12,000 \mathrm{t} / \mathrm{d}$ production line and one $5000 \mathrm{t} / \mathrm{d}$ production line. For the $12,000 \mathrm{t} / \mathrm{d}$ production line, NBC had a positive correlation with the temperature of the calciner outlet, the pressure, and the temperature of the kiln hood, and it had a negative correlation with the quantity of the kiln coal, the temperature of the smoke chamber, and the main motor current of the kiln. The influence degree of each parameter on the NBC is gradually weakened according to the above order. The determination coefficient $\left(R^{2}\right)$ of the model was 0.771, and the mean absolute error and maximum relative error between the predicted and measured NBC were $6.300 \mathrm{mg} / \mathrm{m}^{3}$ and $18.670 \mathrm{mg} / \mathrm{m}^{3}$ respectively.
\end{abstract}

Keywords: nitrogen oxide; soft sensor; ultra-low emission; Pearson coefficient

\section{Introduction}

Most cement enterprises in China use coal as fuel in the cement clinker burning process, and a large number of pollutants, such as $\mathrm{NO}_{\mathrm{X}}$, smoke dust, and sulfur oxide, are released during coal combustion [1], making the cement industry the third largest source of $\mathrm{NO}_{\mathrm{X}}$ emissions after electric power and motor vehicles in China [2]. Cement enterprises generally rely on end-of-pipe control methods to control $\mathrm{NO}_{\mathrm{X}}$ pollution, such as the selective non-catalytic reduction (SNCR) process, the selective catalytic reduction (SCR) process, and staged combustion, of which SNCR is the most widely used [3,4]. SNCR uses ammonia or urea as the reductant to remove $\mathrm{NO}_{\mathbf{X}}$ from the flue gas [4], and the reductant flow is controlled by proportional-integral and derivative control based on the difference between the measured and target values of $\mathrm{NO}_{\mathbf{X}}$. Influenced by factors such as large consumption of inertia, long delays, and multiple disturbances during the cement clinker burning process [5-7], the denitration effects of SNCR systems are not stable, and the $\mathrm{NO}_{\mathbf{X}}$ emission index may exceed the standard in a short period of time. The target $N O_{x}$ emission value for SNCR in many enterprises is usually set below the allowable value [7], and the continuous control of $\mathrm{NO}_{\mathrm{X}}$ emissions is guaranteed by the excessive use of reducing agents. This results in a significant increase in the denitration costs, and the excessive reductant discharged with the flue gas will further cause the "ammonia escape" phenomenon, which triggers new issues, such as the blocking of cloth bags and preheaters, the corrosion of equipment, and the over-standard discharge of fine particles [8]. 
Provinces of China, such as Henan and Shandong, have proposed the concept of ultra-low emissions, with the emission index of $\mathrm{NO}_{X}$ limited to 100 or even $50 \mathrm{mg} / \mathrm{m}^{3}$ [9]. Increasing the amount of reductant in the SNCR process will only aggravate ammonia escape and will not benefit the ultra-low emissions. Some scholars proposed to use biomass for $\mathrm{NO}_{X}$ denitrification in cement production, for instance, Shu Yun [10] adopted three biomass samples: rice husk, sawdust and corncob by reburning to reduce $\mathrm{NO}_{X}$ under different conditions in a fixed-bed reactor, and the maximum $\mathrm{NO}_{X}$ reduction efficiency could reach $57.0 \pm 2.1 \%$, Wang Yali [11] used bamboo charcoal and the best initial denitrification rate could reach $98.906 \%$. However, it should be noted that biomass denitrification is not widely used in cement production, and the actual application effect is still to be verified. Using SCR instead of SNCR to improve the denitration efficiency through catalyst intervention can achieve ultra-low emissions. However, in practical applications, due to the influence of high-dust and low-temperature conditions, the service life and catalytic effect of the catalyst must be further improved [9], and the high cost of SCR is also unappealing to most cement enterprises. Thus, in this paper, a comprehensive measure with optimized working condition parameters is proposed. Staged combustion technology was adopted, and an SNCR control strategy with a "soft sensor" was optimized to realize ultra-low emissions. Furthermore, the modeling of $\mathrm{NO}_{\mathrm{X}}$ emissions is introduced.

\section{Cement Clinker Burning Process and $\mathrm{NO}_{\mathrm{X}}$ Formation Mechanism}

The cement clinker burning process starts from raw material entering the preheater and ends at the grate cooler after the calcined clinker is rapidly cooled. The main equipment includes a preheater, calciner, rotary kiln, and grate cooler, as shown in Figure 1. The raw material after exchanging heat with the hot flue gas discharged from the calciner in the preheater enters the calciner to carry out most of the decomposition of calcium carbonate. The heat needed for the reaction is mainly provided by the tertiary air from the grate cooler, the hot flue gas discharged from smoke chamber of the rotary kiln, and the combustion heat of pulverized coal fed into the calciner. The decomposed material enters the rotary kiln to complete the follow-up solid-phase reaction and form clinker under the heat released by the combustion of pulverized coal in the kiln and the continuous rotation of the rotary kiln. Finally, the clinker enters the subsequent unit after rapid cooling in the grade cooler. The chemical reactions needed for the formation of the cement clinker mainly occur in the calciner and rotary kiln, as does the formation of $\mathrm{NO}_{X}$.

The nitrogen oxide generated in the cement clinker burning process is mainly divided into thermal-NOX and fuel-NOX [12], wherein thermal-NOX refers to the $\mathrm{NO}_{\mathbf{X}}$ generated by the oxidation of $\mathrm{N}_{2}$ in the air at high temperatures, and fuel- $\mathrm{NO}_{X}$ refers to the $\mathrm{NO}_{X}$ generated by the oxidation of nitrogen compounds contained in the fuel entering the cement clinker burning system after thermal decomposition in the combustion process [3]. Thermal-NOX is mainly generated in the rotary kiln, and its generation is mainly affected by the calcination temperature, followed by the concentrations of $\mathrm{O}_{2}$ and $\mathrm{N}_{2}$ and their residence time in the kiln, according to the Zeldovich theory. In contrast, fuel-NO $\mathrm{N}_{\mathrm{X}}$ can be generated in both the calciner and rotary kiln. Its generation is mainly affected by the consumption and properties [13-18] of the fuel, such as the volatile matter, nitrogen content, calorific value, and fixed carbon. Fuel- $\mathrm{NO}_{X}$ generation is closely related to the combustion conditions, such as the temperature and oxygen concentration [3]. It should also be noted that incomplete combustion of the fuel will occur when the air volume into the system is less than the required volume or the properties of the fuel are poor. In this case, reductive $\mathrm{CO}$ gas will be generated, and the following chemical reaction will occur to cause the reduction of $\mathrm{NO}_{\mathbf{X}}$ :

$$
\mathrm{NO}+\mathrm{CO}=\frac{1}{2} \mathrm{~N}_{2}+\mathrm{CO}_{2}
$$



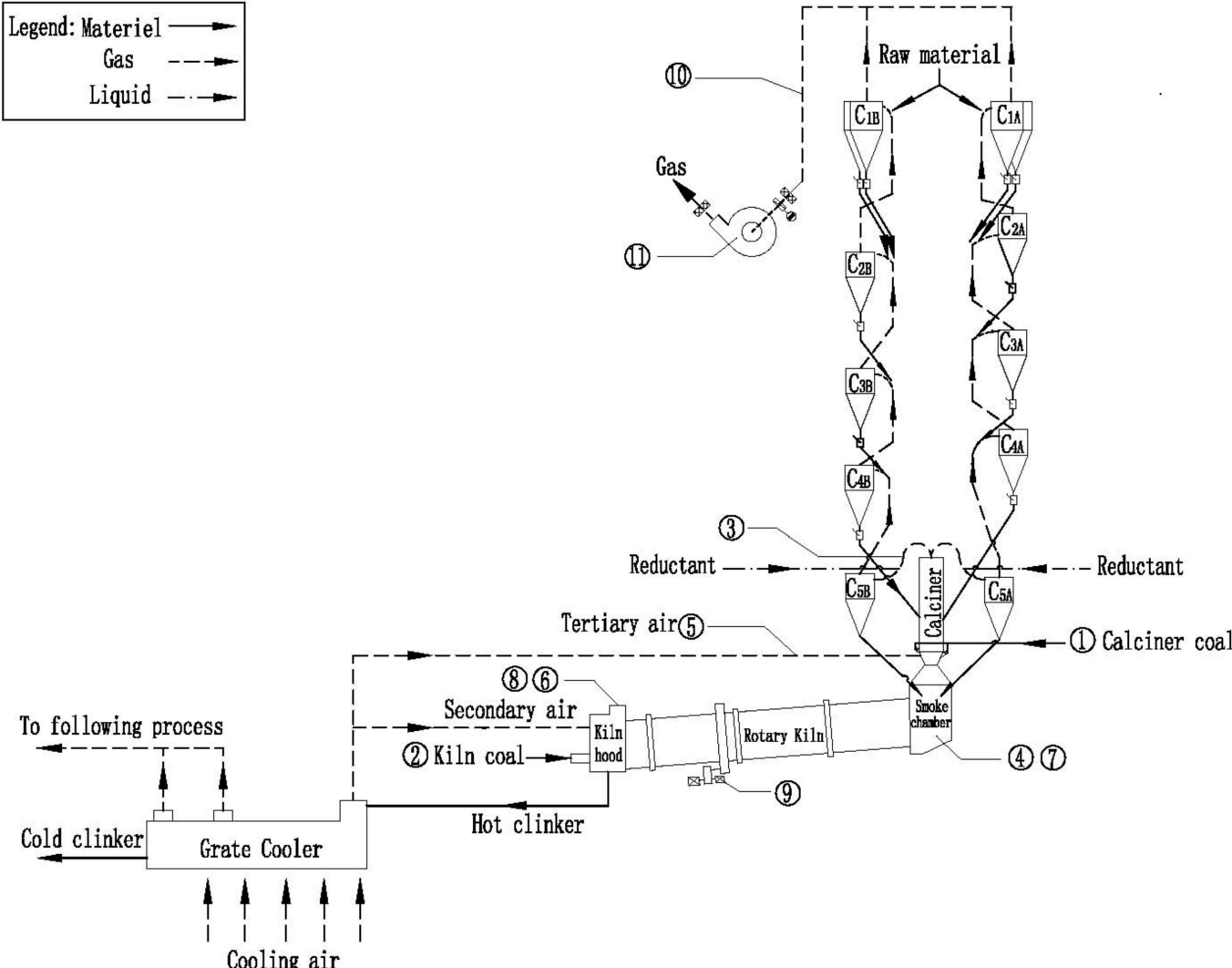

Figure 1. Flow chart of cement clinker burning system.

\section{Technology Route of NOx Ultra-Low Emission}

The $\mathrm{NO}_{\mathrm{X}}$ emission index is an environmental protection ordinance $\left(\mathrm{C}_{\mathrm{NO}_{\mathrm{Xp}}}\right)$, and the actual $\mathrm{NO}_{\mathrm{X}}$ content in flue gas $\left(C_{\mathrm{NO}_{\mathrm{xs}}}\right)$ can be converted as follows:

$$
C_{\mathrm{NO}_{\mathrm{xp}}}=C_{\mathrm{NO}_{\mathrm{xs}}}(21-10) /\left(21-\mathrm{O}_{2}\right)
$$

where $\mathrm{O}_{2}$ represents the actual oxygen content (\%) in the exhaust flue gas of the burning system; its value is mostly controlled at about $1 \%$ in actual production. According to Equation (2), when only SNCR is adopted and its denitration efficiency reaches $60 \%$ (its actual efficiency is $40-60 \%$ [9]), the $\mathrm{NO}_{\mathrm{X}}$ background concentration $(\mathrm{NBC})$ during the burning process should be controlled to within $454.4 \mathrm{mg} / \mathrm{m}^{3}$. At this NBC, the $\mathrm{NO}_{X}$ content in the exhaust flue gas of a burning system after denitration can be lower than $181.8 \mathrm{mg} / \mathrm{m}^{3}$, and an ultra-low emission index of $100 \mathrm{mg} / \mathrm{Nm}^{3}$ can be achieved. Unfortunately, field measurements of several domestic production lines show that the mean value of the $\mathrm{NBC}$ can reach about $1200 \mathrm{mg} / \mathrm{m}^{3}$. Therefore, measures must be taken to reduce the $\mathrm{NO}_{\mathrm{X}}$ background concentration.

The realization of ultra-low emissions cannot be achieved at the cost of increasing the ammonia escape. Ammonia escape is caused by an excess amount of reductant, and the reductant flow is theoretically determined by the NBC. Thus, ammonia escape can be reduced by precise control of the reductant based on the real-time acquisition of the NBC.

The following implementation routes of ultra-low emissions based on SNCR are formulated in this paper:

\subsection{Reduction of $\mathrm{NO}_{\mathrm{X}}$ Background Concentration}

Coal properties and clinker production capacity are relatively stable in most cement enterprises, and the approaches for reducing the $\mathrm{NO}_{\mathrm{X}}$ background concentration include reducing the unit coal 
consumption and optimizing the burning parameters that affect the NBC. Heat consumption can be reduced by means of a technological transformation, such as equipment upgrading and process modifications. Heat consumption can also be slightly improved by the optimization of the burning parameters, which refers to determining and optimizing the key parameters affecting the background concentration of $\mathrm{NO}_{X}$ based on the $\mathrm{NO}_{X}$ generation mechanism. For specific enterprises, whether to carry out technical modifications and which modification mode to use should be determined by the existing process and the configuration of the main equipment.

The first prerequisite of the optimization of the burning parameters is to find the key parameters, which can be divided into the following four categories according to $\mathrm{NO}_{\mathrm{X}}$ generation mechanism and the distribution of the distributed control system (DCS) signals in cement enterprises.

1. Fuel consumption

Fuel consumption refers to the sum of the kiln and calciner coal, which can be obtained from the flow metering equipment (1) and (2) in Figure 1).

\section{Calcination temperature}

The calcination temperature includes the calcination temperature in the rotary kiln and calciner. The temperature of the calciner refers to the outlet temperature of the calciner (3) in Figure 1), and the temperature of the rotary kiln can be calculated [19] based on the volume of the secondary air, the temperature of the secondary air (refers to the temperature of the kiln hood, (6) in Figure 1), the temperature of the smoke chamber (4) in Figure 1), the temperature of the raw material fed into the kiln (same value as the outlet temperature of the calciner), in which the volume of the secondary air can be indirectly determined from the pressure of the kiln hood (8) in Figure 1), and the pressure of the smoke chamber (7) in Figure 1).

An experienced operator in a cement plant also evaluates the temperature of the rotary kiln based on the temperature of the secondary and tertiary air (5) in Figure 1), as well as the current of the kiln motor (9) in Figure 1): larger values of the current and temperatures of the secondary and tertiary air usually correspond to higher rotary kiln temperatures.

\section{Gas concentration}

The gas concentration in the rotary kiln can be calculated based on the volume of secondary air and the consumption of kiln coal. The gas concentration in the calciner can be calculated based on the sum of the consumption of the kiln coal and calciner coal and the volume of the system air, among which the volume of the system air can be determined based on the speed of the high temperature fan (i1) in Figure 1).

\section{Combustion efficiency of coal}

The combustion efficiency of the coal can be obtained by the $\mathrm{CO}$ concentration detected by the gas analyzer at the outlet of the preheater (10 in Figure 1). The key burning parameters affecting the background concentration of $\mathrm{NO}_{\mathrm{X}}$ and their corresponding DCS signal are summarized in Table 1 .

Being affected by differences in the process, the production scale, and the equipment in the production lines, the parameter values vary. Even for two identical production lines, key parameters affecting the NBC would be different due to the distinct nature of the raw materials and fuel. For a specific production line, the key parameters can be identified by secondary screening based on the Pearson correlation coefficient after obtaining the signals of the parameters in Table 1. Details of the secondary screening are presented in Section 6.3 in this article. 
Table 1. Summary of key burning parameters.

\begin{tabular}{|c|c|c|c|c|c|c|c|c|c|c|c|}
\hline \multirow[b]{2}{*}{ Parameters } & \multicolumn{2}{|c|}{ Quantity of Coal } & \multicolumn{4}{|c|}{ Temperature } & \multicolumn{2}{|c|}{ Pressure } & \multirow{2}{*}{$\begin{array}{l}\text { Current of Kiln } \\
\text { Motor }\end{array}$} & \multirow{2}{*}{$\begin{array}{c}\mathrm{CO} \text { at Preheater } \\
\text { Outlet }\end{array}$} & \multirow{2}{*}{$\begin{array}{l}\text { Speed of High } \\
\text { Temperature Fan }\end{array}$} \\
\hline & Calciner Coal & Kiln Coal & $\begin{array}{l}\text { Outlet of } \\
\text { Calciner }\end{array}$ & $\begin{array}{c}\text { Smoke } \\
\text { Chamber }\end{array}$ & Tertiary Air & Secondary Air & $\begin{array}{c}\text { Smoke } \\
\text { Chamber }\end{array}$ & Kiln Hood & & & \\
\hline Unit & $t / h$ & $t / h$ & ${ }^{\circ} \mathrm{C}$ & ${ }^{\circ} \mathrm{C}$ & ${ }^{\circ} \mathrm{C}$ & ${ }^{\circ} \mathrm{C}$ & $\mathrm{Pa}$ & $\mathrm{Pa}$ & A & $\%$ & $\mathrm{rpm}$ \\
\hline Symbol & $x_{1}$ & $x_{2}$ & $x_{3}$ & $x_{4}$ & $x_{5}$ & $x_{6}$ & $x_{7}$ & $x_{8}$ & $x_{9}$ & $x_{10}$ & $x_{11}$ \\
\hline
\end{tabular}




\subsection{Implementation of Staged Combustion}

Staged combustion is usually implemented at the bottom of the calciner, where the evolution of fuel nitrogen from the coal under oxygen-starved conditions leads to $\mathrm{N}_{2}$ formation without $\mathrm{NO}$ as an intermediate thus to reduce the NBC. The denitration efficiency of staged combustion can reach $30-50 \%$. Staged combustion can be realized by the classification of both coal and air, and the specific scheme must be designed based on the specific circumstances of the production line.

\subsection{Optimization of Selective Non-Catalytic Reduction (SNCR)}

The optimization of the SNCR includes the optimization of the hardware and the software. Hardware optimization refers to the improvement of the structure and the installation location of the reductant spray gun. Optimization is conducted using advanced instruments and theoretical analysis to improve the reaction efficiency between the reductant and $\mathrm{NO}_{\mathbf{X}}$. Software optimization in this paper refers to the precise online control strategy based on the real-time acquisition of the NBC. Before the implementation of a precise online control strategy based on the NBC, the actual denitration efficiency of the current SNCR should be accurately determined, which can be obtained by the $\mathrm{NO}_{\mathrm{X}}$ concentration of the flue gas before and after denitration.

\section{Previous Models of $\mathrm{NO}_{\mathrm{X}}$ Background Concentration (NBC)}

As measures to reduce the heat consumption of the clinker burning, staged combustion and the optimization of the SNCR hardware have been widely used in practice. For instance, taking advantage of high solid-gas ratio suspension-preheating decomposition technology [20], the NBC could be reduced to below $600 \mathrm{mg} / \mathrm{Nm}^{3}$. In contrast, limited by severe conditions, such as the high temperatures and high dust content in the calciner, the feasibility of real-time measurements of the NBC with existing instruments is quite low. Accordingly, determining how to obtain the background concentration of $\mathrm{NO}_{X}$ in real time becomes the primary problem to be solved.

Drawing support from soft sensor technology [21,22], a prediction model of the NBC can be established to obtain the real-time NBC from the process parameters obtained online. Prior to this study, scholars such as Lv [23], Zheng [24], Zhou [25], Jin [26], and Zhang [27] predicted NOX concentrations with soft sensor models based on support vector machine (SVM) and neural network methods. This also suggests that the prediction effect of the soft sensor is directly related to the selected model. For example, Wang [28] adopted two soft sensor models to predict the $\mathrm{NO}_{\mathrm{X}}$ concentration in a cement kiln, and the prediction effect of the neural network model was slightly better than that of the linear regression model. The key parameters affecting the $\mathrm{NO}_{X}$ concentration obtained by the two models were different. $\mathrm{Li}$ [29] drew the conclusion that the performance of a support vector machine was better than that of a back-propagation neural network when predicting the $\mathrm{NO}_{\mathrm{X}}$ concentration in a power plant boiler.

\section{Model Structure and Evaluation Index}

\subsection{Model Structure}

A multiple linear regression model was adopted in this study to establish a predictive model for the NBC due to its simple structure and high calculation speed. A multiple linear regression model expresses the quantitative linear relationship between two or more independent variables $x$ and one dependent variable $y$. In this paper, the dependent variable $y$ refers to the NBC, which can be detected by an instrument. It was affected by non-random factors $x_{1}, x_{2}, \ldots, x_{\mathrm{m}}$ and a random factor $\varepsilon$, as follows:

$$
y=\beta_{0}+\beta_{1} x_{1}+\beta_{2} x_{2}+\mathrm{L}+\beta_{\mathrm{m}} x_{\mathrm{m}}+\varepsilon
$$


non-random factors refer to the process parameters that affect the NBC, such as the temperature, current, and consumption of coal. N independent measurements were carried out, and $n$ groups of samples were obtained, which can be expressed as follows:

$$
\left\{\begin{array}{c}
y_{1}=\beta_{0}+\beta_{1} x_{11}+\beta_{2} x_{12}+L+\beta_{n} x_{1 \mathrm{~m}}+\varepsilon_{1} \\
y_{2}=\beta_{0}+\beta_{1} x_{21}+\beta_{2} x_{22}+L+\beta_{n} x_{2 \mathrm{~m}}+\varepsilon_{2} \\
\cdots \\
y_{\mathrm{n}}=\beta_{0}+\beta_{1} x_{\mathrm{n} 1}+\beta_{2} x_{\mathrm{n} 2}+L+\beta_{\mathrm{n}} x_{\mathrm{nm}}+\varepsilon_{\mathrm{n}}
\end{array}\right.
$$

parameters $\varepsilon_{1}, \varepsilon_{2}, \ldots, \varepsilon_{\mathrm{n}}$ were independent of each other, and $\beta_{0}, \beta_{1}, \ldots, \beta_{m}$ in Equation (3) were unknown parameters, which were estimated by the classical least squares method. The resulting linear model can be expressed in matrix form:

$$
\left\{\begin{array}{l}
Y=X \beta+\varepsilon \\
\varepsilon \sim N\left(1, \delta^{2} I_{N}\right)
\end{array}\right.
$$

\subsection{Evaluation Index}

\section{Pearson correlation coefficient}

Multicollinearity between the process parameters must be guaranteed to be weak to avoid the distortion of the model caused by the high correlation between process parameters. The Pearson correlation coefficient $r$ between two process parameters was used to measure the correlation degree between process parameter $x_{\mathrm{a}}$ and process parameter $x_{\mathrm{b}}[30,31]$ in this study. The formula for $r$ is as follows:

$$
Q_{x_{\mathrm{a}} x_{\mathrm{b}}}=\sum_{i=1}^{n}\left(x_{\mathrm{ai}}-\bar{x}_{\mathrm{a}}\right)\left(x_{\mathrm{bi}}-\bar{x}_{\mathrm{b}}\right) / \sqrt{\sum_{i=1}^{n}\left(x_{\mathrm{ai}}-\bar{x}_{\mathrm{a}}\right)^{2} \sum_{i=1}^{n}\left(x_{\mathrm{bi}}-\bar{x}_{\mathrm{b}}\right)^{2}}
$$

where $\overline{x_{\mathrm{a}}}$ and $\overline{x_{\mathrm{b}}}$ are the mean values of the parameters $x_{\mathrm{a}}$ and $x_{\mathrm{b}}$, respectively. The correlation degree between the process parameters can be divided into five categories based on the absolute value of $r$ $(|\mathrm{r}|)$, as shown in Table 2.

Table 2. Correlation degree between process parameters.

\begin{tabular}{cccccc}
\hline$|r|$ & $0 \sim 0.2$ & $\mathbf{0 . 2 \sim 0 . 4}$ & $\mathbf{0 . 4} \mathbf{0 . 6}$ & $\mathbf{0 . 6 \sim 0 . 8}$ & $\mathbf{0 . 8 \sim 1}$ \\
\hline Correlation degree & Irrelevant weak & Weak & Moderate & Strong & Extremely strong \\
\hline
\end{tabular}

\section{Determination coefficient $R^{2}$}

The determination coefficient of the linear regression results $\left(R^{2}\right)$ reflects how much of the variation of the dependent variable $y$ can be described by the fluctuations of the independent variable $x$. The closer $R^{2}$ is to 1 , the better the effect of linear regression is. The determination coefficient $R^{2}$ can be calculated as follows:

$$
\begin{aligned}
R^{2} & =\frac{\sum_{i}\left(\hat{y}_{i}-\bar{y}\right)^{2}}{\sum_{i}\left(y_{i}-\bar{y}\right)^{2}} \\
\bar{y} & =\frac{1}{n} \sum_{i=1}^{n} y_{i}
\end{aligned}
$$

in Equation (7), $y_{i}$ is the measured value of dependent variable and $\hat{y}_{\mathrm{i}}$ is the predicted value. 


\section{Mean absolute error}

The mean absolute error (MAE) was used to measure the prediction effect of the model, and it can be calculated as follows:

$$
\operatorname{MAE}=\frac{1}{n} \sum_{i=1}^{n}\left|y_{\mathrm{i}}-\hat{y}_{\mathrm{i}}\right|
$$

a smaller MAE indicates that the predicted $\mathrm{NO}_{X}$ value is closer to the measured $\mathrm{NO}_{\mathrm{X}}$ value and the prediction effect is relatively better.

\section{Model Development}

A soft sensor model of the $\mathrm{NO}_{\mathrm{X}}$ was developed based on the actual data of a $12,000 \mathrm{t} / \mathrm{d}$ cement clinker production line. The production line is located in Anhui Province. Its actual output is $12,300 \mathrm{t} / \mathrm{d}$, and the annual heat consumption of per clinker is $2959 \mathrm{~kJ} / \mathrm{kg}$. The production line only uses SNCR for denitration, and an aqueous ammonia solution is used as the reductant. Its injection position is near the outlet of the calciner. The local $\mathrm{NO}_{\mathrm{X}}$ index is $400 \mathrm{mg} / \mathrm{m}^{3}$, and the internal index of the enterprise is below $320 \mathrm{mg} / \mathrm{m}^{3}$.

\subsection{Collection of Original Data}

\subsubsection{Collection of NBC}

The NBC data was measured by portable flue gas analyzer (model: Testo 350), and the data collection frequency was $0.1 \mathrm{~Hz}$. The measurement point was $2 \mathrm{~m}$ from injection position of the reductant. In consideration of the large dust content in the flue gas, a dust filter device (4 in Figure 2) was added in the middle of the gas intake pipe to prevent blocking of the analyzer.

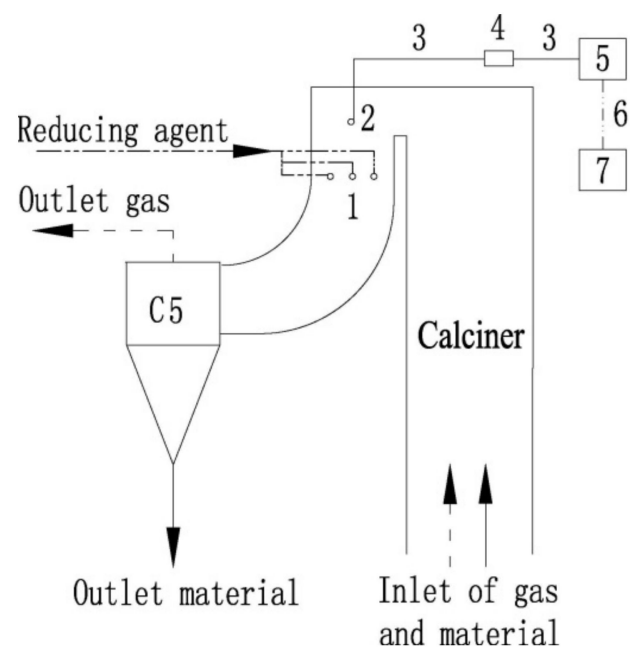

Figure 2. Schematic diagram of $\mathrm{NO}_{X}$ background concentration $(\mathrm{NBC})$ acquisition device. 1: reducing agent spray gun; 2: measuring point; 3 : gas pipeline; 4: dust filter; 5: portable flue gas analyzer; 6: data transmission line; 7: computer.

\subsubsection{Collection of Process Parameters}

The data of the required process parameters was obtained through the DCS server, and its acquisition frequency was $0.1 \mathrm{~Hz}$.

\subsection{Data Preprocessing}

Measurement of the NBC was carried out when the production line operated properly, and the collection of the process parameters was carried out synchronously. A total of 1000 sets 
of original data were obtained, and each set contained 11 values of the process parameters and 1 simultaneous value of the NBC. The original data were preprocessed as follows.

1. Elimination of abnormal data

The filter element at the front of the analyzer needed to be cleaned or replaced regularly due to the influence of the dust in the flue gas, which required about 3 min each time. Correspondingly, the NBC and process parameter values collected in this period were eliminated as abnormal data, and 690 sets of effective data were obtained after elimination.

\section{Mean filter}

Influenced by the working principles and operating conditions of the equipment, the collected signals fluctuated regularly with certain periods. For instance, the range of current of the kiln motor is 700-850 A, and its fluctuation period was $400 \mathrm{~s}$ (Figure 3). The characteristics of the parameters would not be reflected accurately if an instantaneous value at one particular time was used for analysis, and the resulting model would not be representative.

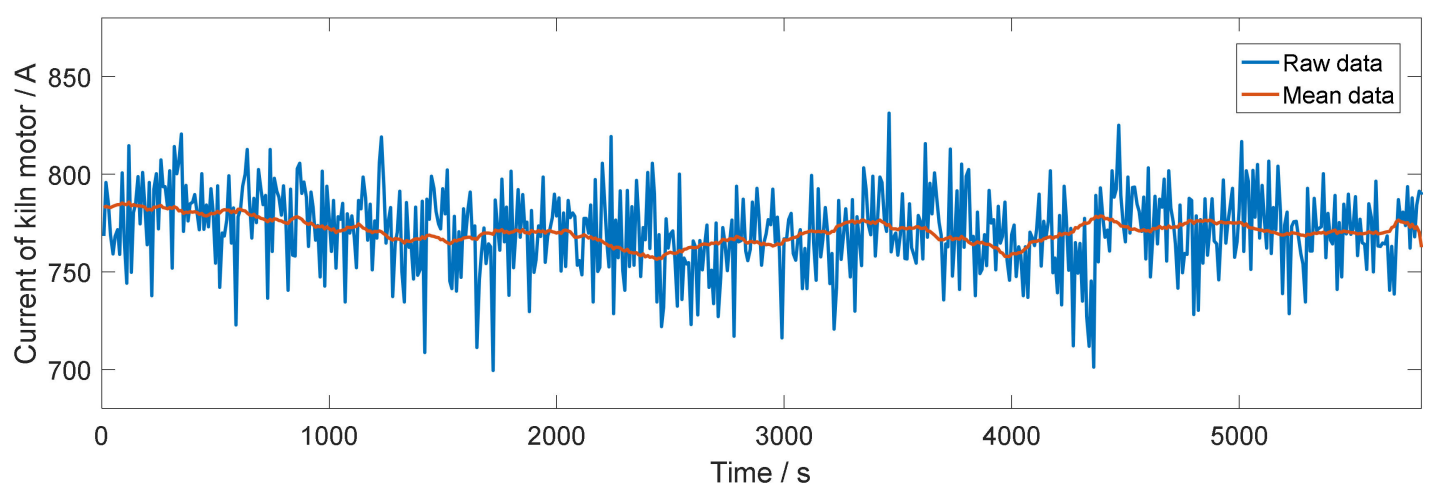

Figure 3. Current trend of kiln main motor.

Therefore, a mean filter was adopted. The window length of the mean filter was determined by the maximum fluctuation period of all the parameters, which was 40 . Thus, the mean matrix A was obtained. Its first row contained the mean values of the parameters from 0 to $400 \mathrm{~s}$, the second row contained the mean values of the parameters from 10 to $410 \mathrm{~s}$, and so on.

\subsection{Selection of Key Process Parameters}

The key process parameters were mainly determined based on the Pearson coefficient. The reliability of the parameters was also considered, and main results are shown in Table 3.

Table 3. Part of Pearson correlation coefficient between process parameters.

\begin{tabular}{cccc}
\hline \multicolumn{2}{c}{ Parameters } & & \\
\cline { 1 - 2 } Parameter $\mathbf{1}$ & Parameter $\mathbf{r}$ & & Retained Parameters \\
\hline$x_{1}$ & $x_{3}$ & 0.787 & $x_{3}$ \\
$x_{5}$ & $x_{9}$ & 0.776 & $x_{9}$ \\
$x_{11}$ & $x_{9}$ & 0.923 & $x_{9}$ \\
$x_{7}$ & $x_{9}$ & 0.869 & $x_{9}$ \\
$x_{10}$ & $x_{4}$ & 0.862 & $x_{4}$ \\
\hline
\end{tabular}

(1) The quantity of the calciner coal was strongly related to the temperature of the calciner outlet and, thus, one of the two parameters needed to be eliminated. Considering that the signal reliability of the calciner coal quantity was lower than that for the temperature data, as the coal quantity often 
exhibited certain deviations due to the low accuracy of the metering instrument and the poor operating environment, the temperature of the calciner outlet $x_{3}$ was retained.

(2) The current of the kiln motor had a strong correlation with the temperature of the tertiary air, the speed of the high temperature fan, and the pressure of the smoke chamber. Only the current of the kiln motor was reserved for subsequent analysis, because it is one of the most important parameters in the clinker firing process. Furthermore, its reliability and accuracy were much higher than those of parameters such as the temperature and pressure.

(3) There was a strong correlation between the $\mathrm{CO}$ concentration at the preheater outlet and temperature of the smoke chamber. The $\mathrm{CO}$ concentration at the outlet of the preheater was obtained by an on-line gas analyzer, which required blowback regularly. The detection value was abnormal during blowback. Furthermore, to reduce the cost, most cement enterprises opt to use gas analyzers with low accuracies or to not use on-line analyzers. Thus, the CO concentration at the preheater outlet was eliminated as a parameter.

Based on the above analysis, the key parameters affecting the NBC of 12,000 $\mathrm{t} / \mathrm{d}$ production line were finally determined to be the quantity of the head coal $x_{2}$, the temperature of the calciner outlet $x_{3}$, the temperature of the smoke chamber $x_{4}$, the temperature of the kiln hood $x_{6}$, the pressure of the kiln hood $x_{8}$, and the current of the kiln motor $x_{9}$.

\subsection{Development of NBC Model}

Taking $x_{2}, x_{3}, x_{4}, x_{6}, x_{8}$, and $x_{9}$ as the independent variables and the NBC as the dependent variable, a matrix B with 695 rows and 4 columns was obtained. B was normalized as follows:

$$
x_{\text {norm }}=\left(\mathrm{x}-x_{\min }\right) /\left(x_{\max }-x_{\min }\right)
$$

where $x_{\text {norm }}$ is the normalized data, $x$ is the original data, and $x_{\min }$ and $x_{\max }$ are the minimum and maximum values of the original data, respectively.

Considering the possible fluctuations of the working conditions, the values of $x_{\min }$ and $x_{\max }$ were adjusted based on the actual maximum $\left(x_{\mathrm{rmax}}\right)$ and actual minimum $\left(x_{\mathrm{rmin}}\right)$ of the collected data, which are shown in Table 4.

The normalized matrix $C$ was obtained, and the first 400 rows of matrix $C$ were selected as training data. A predictive model of the NBC was developed based on the multiple linear regression method; the main parameters are shown in Tables 5 and 6.

Table 4. Extreme values of parameters.

\begin{tabular}{cccccccc}
\hline Parameters & $x_{2}$ & $x_{3}$ & $x_{4}$ & $x_{6}$ & $x_{8}$ & $x_{9}$ & $y$ \\
\hline$x_{\text {rmax }}$ & 22.8 & 875.6 & 1197.6 & 799.3 & -61.8 & 1301.5 & 662.0 \\
$x_{\text {rmin }}$ & 22.7 & 872.5 & 1188.8 & 764.3 & -75.9 & 1266.9 & 616.0 \\
$x_{\min }$ & 23.0 & 880.0 & 1210.0 & 810.0 & -50.0 & 1310.0 & 680.0 \\
$x_{\max }$ & 22.0 & 865.0 & 1170.0 & 750.0 & -85.0 & 1250.0 & 600.0 \\
\hline
\end{tabular}

Table 5. Regression statistics.

\begin{tabular}{cccccc}
\hline Item & Multiple R & $\boldsymbol{R}^{\mathbf{2}}$ & Adjusted R Square & Standard Error & Observation Value \\
\hline Value & 0.878 & 0.771 & 0.768 & 0.080 & 400 \\
\hline
\end{tabular}

Table 6. Analysis of variance (ANOVA) table.

\begin{tabular}{cccccc}
\hline & df & SS & MS & F & Significance F \\
\hline Regression analysis & 6 & 8.496 & 1.416 & 220.926 & $1.4 \times 10^{-122}$ \\
Residual & 393 & 2.519 & 0.006 & & \\
Total & 399 & 11.015 & & & \\
\hline
\end{tabular}


The $R^{2}$ of the linear regression was 0.771 , and the significance $F$ was far less than 0.001 . Therefore, conclusions can be drawn that the developed model was statistically significant. According to the regression coefficient in Table 7, the regression equation for NBC in the 12,000 t/d cement clinker burning system was as follows:

$$
\begin{gathered}
y_{\text {norm }}=-2.98 x_{2}+1.44 x_{3}-0.99 x_{4}+0.44 x_{6}+0.77 x_{8}-0.67 x_{9}-0.76 \\
y=80 y_{\text {norm }}+600
\end{gathered}
$$

Table 7. Regression coefficient.

\begin{tabular}{ccccc}
\hline & Coefficients & Standard Error & t Stat & $p$-Value \\
\hline Intercept & 2.232 & 0.335 & 6.663 & $9.073 \times 10^{-11}$ \\
$x_{2}$ & -2.982 & 0.416 & -7.170 & $3.75 \times 10^{-12}$ \\
$x_{3}$ & 1.441 & 0.168 & 8.562 & $2.55 \times 10^{-16}$ \\
$x_{4}$ & -0.995 & 0.186 & -5.334 & $1.62 \times 10^{-7}$ \\
$x_{6}$ & 0.439 & 0.079 & 5.575 & $4.62 \times 10^{-8}$ \\
$x_{8}$ & 0.772 & 0.048 & 16.127 & $2.88 \times 10^{-45}$ \\
$x_{9}$ & -0.666 & 0.044 & -15.266 & $1.21 \times 10^{-41}$ \\
\hline
\end{tabular}

The comparison of the predicted $\mathrm{NO}_{X}$ values using training data and the actual $\mathrm{NO}_{\mathrm{X}}$ values is shown in Figure 4.

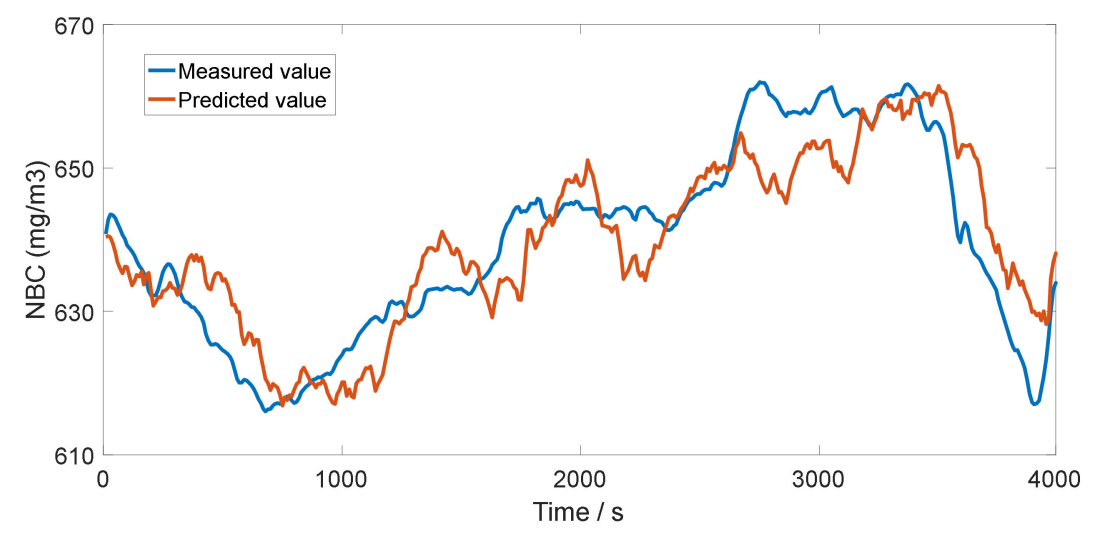

Figure 4. Trend of actual and predicted $\mathrm{NO}_{X}$ value of $12,000 \mathrm{t} / \mathrm{d}$ production line.

Based on the theory of cement technology operation, the obtained model is explained as follows:

(1) The NBC was positively related with the temperature of the calciner outlet $\left(x_{3}\right)$, which was highly related to the amount of calciner coal. A high temperature at the calciner outlet indicated that there was a large amount of calciner coal, and thus, the NBC will increase with the increase in the fuel-NOX.

(2) Based on production experience, when the operation parameters of the grate cooler are fixed, the higher the temperature of the kiln hood, the higher the calcination temperature of the rotary kiln. Consequently, the NBC will increase due to the increase in thermal-NOX. The model showed that the NBC was positively correlated with the temperature of the kiln hood $\left(x_{6}\right)$.

(3) A higher pressure kiln hood indicated that a higher volume of air was in the kiln, and more thermal-NO $\mathrm{NO}_{X}$ could be generated in the kiln according to the Zeldovich theory. Therefore, there was also a positive correlation between the pressure of the kiln hood $\left(x_{8}\right)$ and the NBC.

(4) A spot investigation of the production line showed that more kiln coal than the theoretical demand was provided to ensure that the content of free $\mathrm{CaO}$ in the clinker could be controlled stably below $0.8 \%$. More than 3000 ppm of CO could be detected in the smoke chamber. A series of problems 
was introduced by the excess amount of head coal. First, the viscosity of the material in the kiln increased with the increase in the calcination temperature. Thus, the material could rise to a greater height along the inner wall of the kiln, and the rotary torque of the kiln increased, which resulted in an increase in the current of the kiln motor. Second, reductive $\mathrm{CO}$ produced by the incomplete combustion of the kiln coal caused the reduction of $\mathrm{NO}_{X}$ generated in the kiln. Finally, the remaining $\mathrm{CO}$ after the denitration reaction with $\mathrm{NO}_{\mathrm{X}}$ entered the smoke chamber with hot flue gas, which also contained $\mathrm{O}_{2}$ due to the air leakage from the gap between the smoke chamber and rotary kiln. Thus, the exothermic oxidation reaction between $\mathrm{CO}$ and $\mathrm{O}_{2}$ could be carried out to cause the temperature of the smoke chamber to rise. The above phenomena were consistent with the conclusions from the model, i.e., the amount of kiln coal $\left(x_{2}\right)$, the temperature of the smoke chamber $\left(x_{4}\right)$, and the current of the kiln motor $\left(x_{9}\right)$ had negative correlations with the NBC.

The obtained model was highly consistent with the process theory and has strong interpretability. Using the last 290 sets of matrix C as test data, the values of the NBC predicted by the model and the measured values are shown in Figure 5.

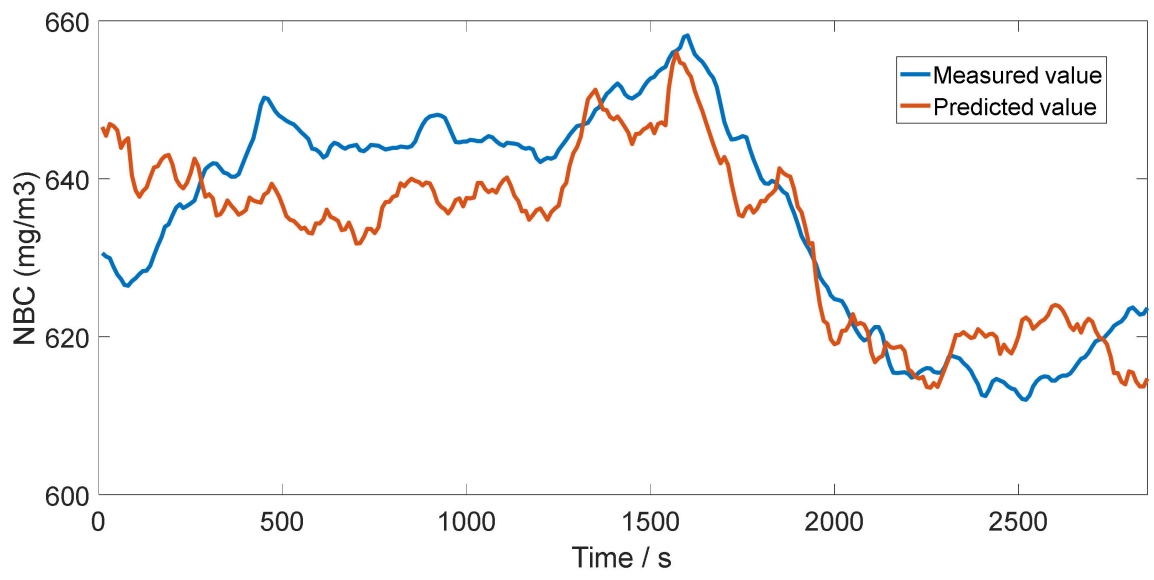

Figure 5. Trend of actual and predicted $\mathrm{NO}_{X}$ value of $12,000 \mathrm{t} / \mathrm{d}$ production line.

The trends of the predicted values were basically consistent with those of the measured values, indicating that the model could cope with the fluctuations of the operating conditions. The MAE between the predicted and measured values of the NBC was $6.300 \mathrm{mg} / \mathrm{m}^{3}$, and the maximum deviation was $18.670 \mathrm{mg} / \mathrm{m}^{3}$ (Figure 6). The error between the maximum deviation value and the NBC was less than $3 \%$; thus, the prediction effect of the model was good.

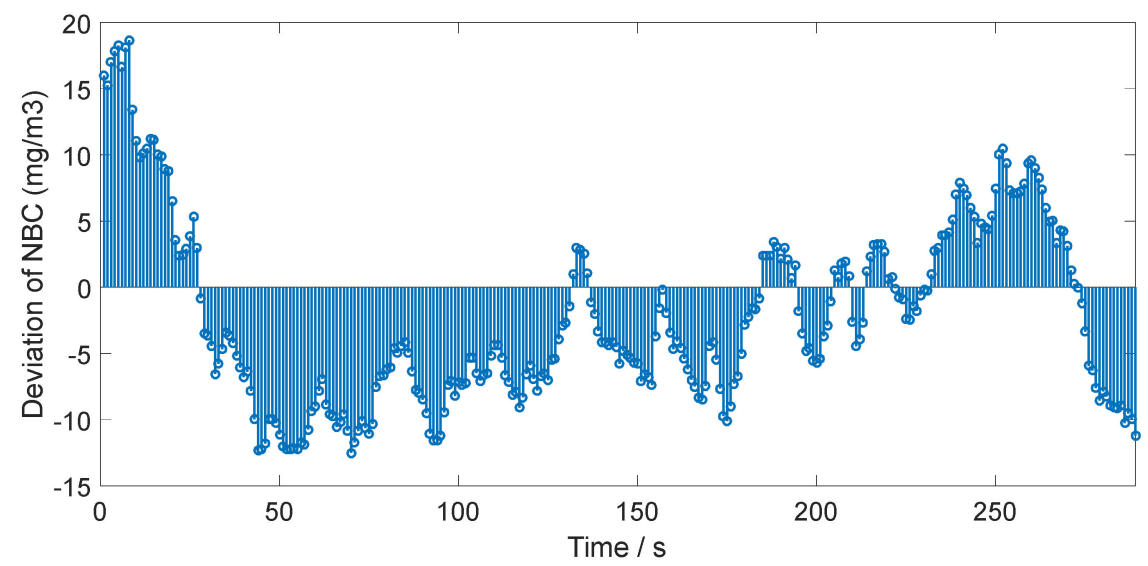

Figure 6. Deviation between predicted value and measured value of $\mathrm{NO}_{\mathrm{X}}$ of $12,000 \mathrm{t} / \mathrm{d}$ production line.

For different production lines, the production parameters affecting the background concentration of $\mathrm{NO}_{\mathrm{X}}$ and their influence rules may be slightly different, which means that the conclusions obtained 
in this paper are not applicable to all production lines. In the popularization and application of the model, the above analysis process must be repeated to ensure the reliability of the results.

\section{Modeling in One $5000 \mathrm{t} / \mathrm{d}$ Production Line}

NBC prediction modeling was also carried out in one $5000 \mathrm{t} / \mathrm{d}$ production line in Guangxi Province according to the same method and process as in Section 5. The production line adopts "XDL cement clinker calcination technology", its actual output is $6351 \mathrm{t} / \mathrm{d}$, and the annual heat consumption of per clinker is $2828 \mathrm{~kJ} / \mathrm{kg}$. Denitration measures and emission control indicators of this $5000 \mathrm{t} / \mathrm{d}$ production line are the same as those of $12,000 \mathrm{t} / \mathrm{d}$ production line.

The key nodes in the modeling process of $5000 \mathrm{t} / \mathrm{d}$ production line are introduced as follows.

\subsection{Determination of Key Process Parameters}

The chosen 11 process parameters of 5000t/d production line for subsequent analysis are the same as those of the $12,000 \mathrm{t} / \mathrm{d}$ production line, which were numbered with $\mathrm{Xi}$ in order to distinguish from the process parameters of the $12,000 \mathrm{t} / \mathrm{d}$ production line, and the sequence of number $i$ is consistent with that in Table 1.

Pearson coefficients of some key process parameters of $5000 \mathrm{t} / \mathrm{d}$ production line are as shown in Table 8.

Table 8. Pearson coefficients of process parameters of $5000 \mathrm{t} / \mathrm{d}$ production line.

\begin{tabular}{|c|c|c|c|}
\hline \multicolumn{2}{|c|}{ Parameters } & \multirow{2}{*}{$|\mathbf{r}|$} & \multirow{2}{*}{ Retained Parameters } \\
\hline Parameter 1 & Parameter 2 & & \\
\hline$X_{1}$ & $X_{9}$ & 0.624 & $X_{9}$ \\
\hline$X_{7}$ & $X_{2}$ & 0.572 & $X_{7}$ \\
\hline$X_{7}$ & $X_{5}$ & 0.752 & $X_{7}$ \\
\hline$X_{7}$ & $X_{6}$ & 0.835 & $X_{7}$ \\
\hline$X_{7}$ & $X_{8}$ & 0.840 & $X_{7}$ \\
\hline
\end{tabular}

(1) The quantity of the calciner coal $X_{1}$ was strongly related to the current of the kiln motor $X_{9}$, and the current of the kiln motor $X_{9}$ was retained because its signal was more reliable.

(2) The pressure of the smoke chamber $X_{7}$ had a strong correlation with the quantity of the kiln coal $X_{2}$, the temperature of tertiary air $X_{5}$, the temperature of secondary air $X_{6}$ and the pressure of the kiln hood $X_{8}$. Only $X_{7}$ was reserved to reduce the number of independent variables and improve the reliability of the model.

Based on the above analysis, the key parameters affecting the NBC of $5000 \mathrm{t} / \mathrm{d}$ production line were finally determined to be the temperature of the calciner outlet $X_{3}$, the temperature of the smoke chamber $X_{4}$, the pressure of smoke chamber $X_{7}$, the current of the kiln motor $X_{9}$, the $\mathrm{CO}$ at preheater outlet $X_{10}$ and the speed of the high-temperature fan $X_{11}$.

\subsection{Development of NBC Model of 5000t/d Production Line}

A total of 950 groups of data were obtained after data processing, and the first 500 groups were selected as training data. The $R^{2}$ of the linear regression of the $5000 \mathrm{t} / \mathrm{d}$ production line was 0.794 , and the $P$ value was far less than 0.001 . Therefore, conclusions can be drawn that the developed model was statistically significant. The regression equation for NBC in the $5000 \mathrm{t} / \mathrm{d}$ cement clinker burning system was as follows:

$$
\begin{gathered}
Y_{\text {norm }}=0.21 X_{3}-0.01 X_{4}-0.19 X_{7}+0.58 X_{9}+0.28 X_{10}-0.12 X_{11}+0.27 \\
Y=208 Y_{\text {norm }}+498
\end{gathered}
$$

The obtained model is explained as follows: 
(1) The same conclusion as the $12,000 \mathrm{t} / \mathrm{d}$ model can be obtained that NBC of the $5000 \mathrm{t} / \mathrm{d}$ production line was positively related with the temperature of outlet of calciner $X_{3}$ and was negatively related with the temperature of smoke chamber $X_{4}$.

(2) Gas components measurement showed that the air excess coefficient of smoke chamber is consistently higher than 1.05 and the quantity of kiln coal is basically unchanged during production. Under the above premise, the increase of pressure of smoke chamber means that the air volume in the kiln is increased, thus the calcination temperature in the high-temperature section of the kiln will be relatively reduced, and the formation rate of thermal nitrogen oxides will be reduced; on the other hand, residence time of air in the kiln would be shortened with the increase of air volume in the kiln. Therefore, NBC would decrease with the increase in pressure of the smoke chamber.

(3) In this $5000 \mathrm{t} / \mathrm{d}$ production line, NBC increases with the increase of the current of kiln motor $X_{9}$. Increase of $X_{9}$ indicates that the raw material in the kiln is fully calcined and the height of the material taken up with the rotation of the rotary kiln could be increased, which will increase the load of the kiln and the kiln current. More thermal $\mathrm{NO}_{\mathrm{X}}$ will be generated when the calcination is sufficient, resulting in the increase of NBC value.

It should be noted that for the 12,000 $\mathrm{t} / \mathrm{d}$ production line, current of kiln motor $X_{9}$ has a negative correlation with NBC, it is inconsistent with $5000 \mathrm{t} / \mathrm{d}$ production line. The reason lies in the fact that calorific value of the incoming coal in the 12,000 t/d production line is low and the flammability is poor due to the influence of coal supply. Excessive kiln coal is adopted to force calcination in kiln consciously thus to stabilize the quality of clinker. The insufficient combustion of excessive kiln coal ensures the high temperature required by the sintering zone in the kiln, improves the calcination effect of the clinker and increases the current of the kiln motor. However, the unburned kiln coal will continue to enter the transition section of kiln with flue gas and burns under weak oxygen atmosphere, where the reductive $\mathrm{CO}$ gas can be generated, thus the thermal $\mathrm{NO}_{\mathbf{X}}$ generated in the kiln would be reduced and NBC value would be decreased. The above conclusion is contrary to the conventional knowledge, but it exists objectively in this $12,000 \mathrm{t} / \mathrm{d}$ production line.

(4) There is a positive correlation between the CO at preheater outlet $X_{10}$ and NBC. The reason lies in the fact that the thickness of the castable for the tertiary air duct in the production line is increased, the effective inner diameter of tertiary air duct is reduced and the tertiary air velocity is as high as $32 \mathrm{~m} / \mathrm{s}$, and the volume of tertiary air is lower than the design value for a long time due to the large resistance loss of the tertiary air duct. Excess air coefficient at the middle of the calciner is only 0.96 and the combustion of calciner coal is not sufficient due to the insufficient supply of tertiary air; part of the calciner coal enters the $\mathrm{C} 5$ cyclone, where the reductive $\mathrm{CO}$ can be formed.

$\mathrm{NO}_{X}$ is mostly generated at the calciner and kiln, which means that the $\mathrm{CO}$ generated in $\mathrm{C} 5$ cyclone would not reduce $\mathrm{NO}_{X}$ and therefore has no impact on NBC; however, when the CO detected at the outlet of preheating system increases, it indicates that the combustion efficiency of calciner coal becomes worse. In this case, measures such as increasing calciner coal and increasing calciner temperature to stabilize production will be adopted, more fuel-NOX will be generated to increase $\mathrm{NBC}$ value. That explains why NBC increases with the increase of CO at preheater outlet in this $5000 \mathrm{t} / \mathrm{d}$ production line.

(5) Due to the limitation of the inner diameter of the tertiary air duct, combustion of the calciner coal is not sufficient. Tertiary air volume can be relatively increased and the combustion efficiency of calciner coal is improved with the increase of high-temperature fan speed, thus the fuel- $\mathrm{NO}_{\mathrm{X}}$ will decrease with the decrease of calciner coal quantity; although the $\mathrm{NO}_{\mathrm{X}}$ generated in the kiln might be increased at the same time, for this $5000 \mathrm{t} / \mathrm{d}$ production line, its NBC decreases with the increase of high-temperature fan speed after the combination of the these two effects.

The obtained model was highly consistent with the process theory and has strong interpretability. The comparison of the predicted $\mathrm{NO}_{X}$ values using training data and the actual $\mathrm{NO}_{\mathrm{X}}$ values is shown in Figure 7, and the values of the NBC predicted by the model and the measured values are shown in Figure 8. 


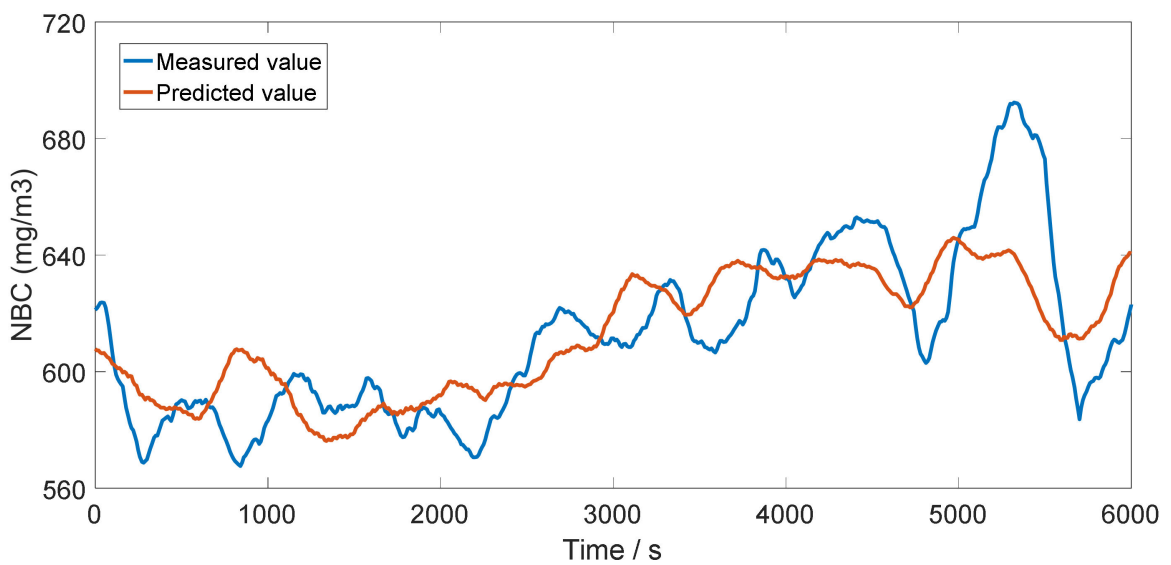

Figure 7. Trend of actual and predicted $\mathrm{NO}_{X}$ value of $5000 \mathrm{t} / \mathrm{d}$ production line.

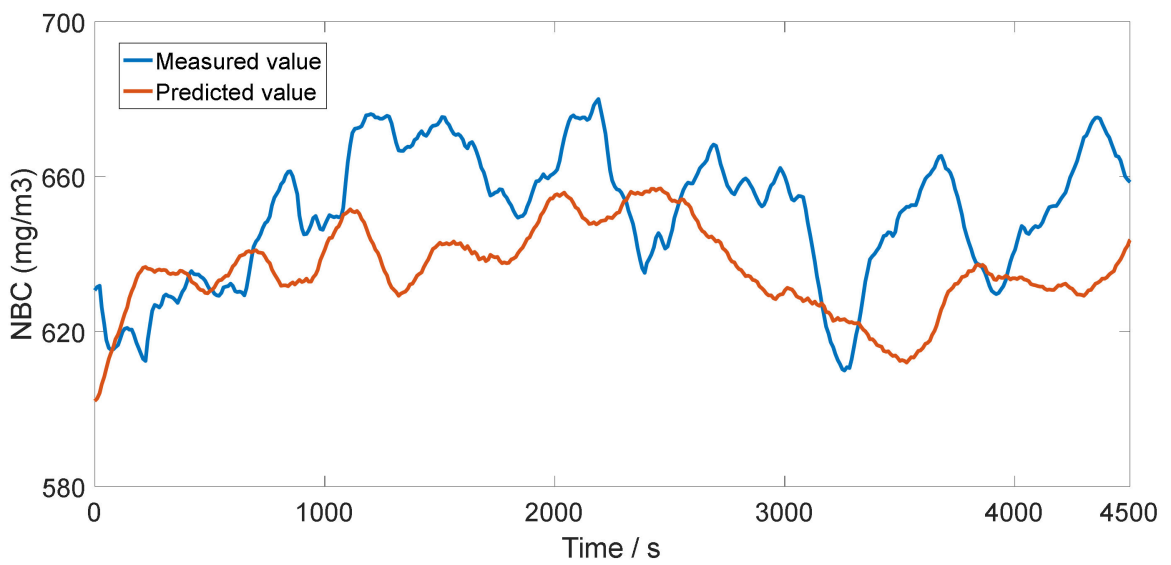

Figure 8. Trend of actual and predicted $\mathrm{NO}_{X}$ value of $5000 \mathrm{t} / \mathrm{d}$ production line.

The MAE between the predicted and measured values of the NBC was $14.817 \mathrm{mg} / \mathrm{m}^{3}$, the error between the maximum deviation value and the NBC was less than $5 \%$, and the prediction effect of the model was good.

\section{Conclusions}

In this paper, the use of SNCR to realize the ultra-low emissions of $\mathrm{NO}_{X}$ in the process of cement burning was proposed, and it contains three steps: reduction of $\mathrm{NO}_{\mathrm{X}}$ background concentration (NBC), implementation of staged combustion, and the optimization of SNCR. The key parameters effects on NBC were studied using soft-sensor technology. The real-time acquisition of NBC in one 12,000 t/d production line and one $5000 \mathrm{t} / \mathrm{d}$ production line was realized by building a multiple linear regression model of the key process parameters and NBC. The conclusions were as follows.

(1) According to the mechanism of $\mathrm{NO}_{X}$ formation, the parameters affecting the background concentration of $\mathrm{NO}_{\mathrm{X}}$ were mainly the fuel consumption, calcination temperature, and gas concentration, and specific parameters will be slightly different with the equipment and operation of different production lines.

(2) For the 12,000 $\mathrm{t} / \mathrm{d}$ production line, its $\mathrm{NO}_{\mathrm{X}}$ background concentration had positive correlations with the temperature of the calciner outlet, the pressure of the kiln hood, and the temperature of the kiln hood; and negative correlations with the quantity of head coal, the temperature of the smoke chamber, and the current of the kiln motor. The MAE between the predicted and measured values of the NBC was $6.300 \mathrm{mg} / \mathrm{m}^{3}$, and the maximum deviation was $18.670 \mathrm{mg} / \mathrm{m}^{3}$.

(3) For the $5000 \mathrm{t} / \mathrm{d}$ production line, its $\mathrm{NO}_{X}$ background concentration had positive correlations with the temperature of the calciner outlet, the current of the kiln motor and $\mathrm{CO}$ at the preheater outlet 
and negative correlations with the temperature of the smoke chamber, the pressure of smoke chamber, and the speed of the high-temperature fan. MAE between the predicted and measured values of the NBC was $14.817 \mathrm{mg} / \mathrm{m}^{3}$, and the error between the maximum deviation value and the NBC was less than $5 \%$.

Author Contributions: Conceptualization, Y.Y. and Y.C.; methodology, Y.Y.; software, Y.Y.; validation, Y.Y.; formal analysis, Y.Y.; investigation, Y.Y.; resources, Y.C.; data curation, Y.Y.; writing-Original draft preparation, Y.Y.; writing-Review and editing, Y.C.; visualization, Y.C.; funding acquisition, Y.C. All authors have read and agreed to the published version of the manuscript.

Funding: This research was funded by NATIONAL KEY R\&D PROGRAM OF CHINA, grant number 2016YFB0303402. The APC was funded by NATIONAL KEY R\&D PROGRAM OF CHINA.

Acknowledgments: Thanks to Bao Yaoyao and Zheng Qinquan of East China University of science and technology for their support on data analysis.

Conflicts of Interest: The authors declare no conflict of interest. The funders had no role in the design of the study; in the collection, analyses, or interpretation of data; in the writing of the manuscript; or in the decision to publish the results.

\section{References}

1. Pan, Y. The Control of NOX Emission of Coal-Fired Boiler. Master's Thesis, North China Electric Power University, Beijing, China, 2017.

2. Lv, G. Experimental and Modeling Study of NO Formation and Reduction for Precalciner. Ph.D. Thesis, Huazhong University of Science and Technology, Wuhan, China, 2011.

3. Liu, X.W. Analysis of environmental impact of cement denitrification technology. China Resour. Compr. Util. 2018, 6, 108-109.

4. Chen, Y.X.; Zhang, X. Discussion on denitration technology of cement. Guangdong Build. Mater. 2016, 8, 33-35. (In Chinese)

5. Tong, C.H. SNCR denitration automatic control system's optimization in guojiawan power plant. Shenhua Sci. Technol. 2018, 2, 57-58, 73.

6. Zhu, Z.J.; Bai, J.Y.; Liu, L.X. Research and application of expert fuzzy control in sncr denitrification system. Process Autom. Instrum. 2018, 7, 34-38.

7. $\mathrm{Ma}, \mathrm{X} . \mathrm{Q}$. Brief talk on treatment of nitrogen oxide and ammonia emission in domestic cement industry. China Cem. 2019, 5, 78-80.

8. Zhao, W.X.; Yang, J.B. Technical renovation of denitration system to solve process accidents caused by excessive ammonia escape. Cem. Guide New Epoch 2017, 1, 52-53. (In Chinese)

9. Li, X.M.; Lin, Y. Ultra low emission and flue gas treatment technology in cement industry. Cem. Eng. 2019, 6, $70-72$.

10. Jiang, P.Z. Application of SNCR in CFB boilers for low $\mathrm{NO}_{\mathrm{X}}$ emission. Electr. Power Standarization Constr. Cost Control Inf. 2010, 6, 6-10.

11. Shu, Y.; Wang, H.Z.; Zhu, J.W.; Zhang, F.; Huang, J. Nitrogen oxide reduction by biomass reburning and its reaction characteristics of homogeneous reduction. Res. Environ. Sci. 2015, 28, 660-666.

12. Wang, Y.L.; Qin, N.N.; Li, N.; Song, Y.H.; Cui, S.P. Study on reaction conditions of bamboo charcoal used in flue gas denitrification of cement kiln. Bull. Chin. Ceram. Soc. 2019, 38, 3552-3558.

13. Wendt, J.O.L.; Pershing, D.W. Physical Mechanisms Governing the Oxidation of Volatile Fuel Nitrogen in Pulverized Coal Flames. Combust. Sci. Technol. 1977, 16, 111-118. [CrossRef]

14. Peter, G.; Miller, J.A.; Kee, R.J. Kinetic Modeling and Sensitivity of Nitrogen Oxides Formation in Well-Stirred Reactor. Combust. Flame 1986, 65, 177-202.

15. Miller, J.A.; Bowman, C.T. Mechanism and Modeling of Nitrogen Chemistry in Combustion. Process Energy Combust. Sci. 1989, 15, 287-338. [CrossRef]

16. Song, Y.H. Nitrogen oxide formation during pulverized. coal combustion. Combust. Sci. Technol. 1982, 28, 31-39. [CrossRef]

17. Zhao, J.S.; Grace, J.R. Influence of operating parameter on $\mathrm{NO}_{\mathrm{X}}$ emissions from a circulating fluidized bed combustor. Fuel 1994, 6, 1651-1656.

18. Thomas, K.R. The release of nitrogen oxides during char combustion. Fuel 1997, 6, 457-471. [CrossRef] 
19. Wang, Y. The Study on Temperature Modeling and Control of Cement Rotary Kiln. Master's Thesis, Tianjin University of Technology, Tianjin, China, 2017.

20. Huo, L.P.; Yang, K.; Xu, D.L.; Ji, Y. Theoretical Analysis on the Advantage of NOX Remove of the Suspension Preheating and Pred Ecomposition System with High Solid-gas Ratio. Bull. Chin. Ceram. Soc. 2014, 3, 656-661.

21. Cao, P.F.; Luo, X.L. Modeling of soft sensor for chemical process. CIESC J. 2013, 3, 788-800.

22. Haimi, H.; Mulas, M.; Corona, F.; Vahala, R. Data-derived soft-sensors for biological wastewater treatment plants: An overview. Environ. Modell. Softw. 2013, 47, 88-107. [CrossRef]

23. Lv, Y.; Liu, J.Z.; Yang, T.T.; Zeng, D. A Novel Least Squares Support Vector Machine Ensemble Model for $\mathrm{NO}_{X}$ Emission Prediction of a Coal-fired Boiler. Energy 2013, 55, 319-329. [CrossRef]

24. Zheng, L.G.; Zhou, H.; Cen, K.F.; Wang, C.L. A comparative study of optimization algorithms for low $\mathrm{NO}_{X}$ emission modification at a coal-fired utility boiler. Expert Syst. Appl. 2009, 36, 2780-2793. [CrossRef]

25. Zhou, H.; Mao, J.B.; Chi, Z.H.; Jiang, X.; Wang, Z.; Cen, K. Predicting Low $\mathrm{NO}_{X}$ Combustion Property of a Coal-fired Boiler. Environ. Sci. 2002, 2, 18-22.

26. Jin, X.Z.; Zhang, S.K. Prediction of denitrification system inlet nitrogen oxide based on neural network online learning. J. Hebei Univ. (Nat. Sci. Ed.) 2018, 4, 423-431.

27. Zhang, H.; Zhou, C.C.; Ren, P. Prediction Model of Boiler NOX Emission Based on Least Squares Support Vector Machine. Jilin Electr. Power 2019, 3, 18-20.

28. Wang, W.Q. Simulation and Optimization of Oxynitride Emissions During the Process of Cement Precalcining Kiln. Master's Thesis, Dalian University of Technology, Dalian, China, 2017.

29. Li, K. Research on Boiler Nitrogen Oxide Prediction and Reduction Based on Data Mining. Master's Thesis, Huazhong University of Science and Technology, Wuhan, China, 2019.

30. Rodgers, J.L.; Nicewander, W.A. Thirteen ways to look at the correlation coefficient. Am. Stat. 1988, 1, 59-66. [CrossRef]

31. Wei, Y.C. A novel d-s combination method of conflicting evidences based on pearson correlation coefficient. Telecommun. Eng. 2012, 4, 466-471.

(C) 2020 by the authors. Licensee MDPI, Basel, Switzerland. This article is an open access article distributed under the terms and conditions of the Creative Commons Attribution (CC BY) license (http://creativecommons.org/licenses/by/4.0/). 